\title{
Rosiglitazone alleviates myocardial apoptosis in rats with acute myocardial infarction via inhibiting TLR4/NF-kB signaling pathway
}

\author{
HONGZHONG MA ${ }^{1 *}$, JUAN DU $^{1 *}$, XIAOLI FENG ${ }^{2}$, YINGJUN ZHANG $^{3}$, HAIHUAN WANG $^{1}$, \\ SUCHUN DING ${ }^{1}$, AIJIE HUANG ${ }^{1}$ and JIAHAI MA ${ }^{1}$
}

Departments of ${ }^{1}$ Anesthesiology and ${ }^{2}$ Pathology, The Affiliated Yantai Yuhuangding Hospital of Qingdao University, Yantai, Shandong 264000; ${ }^{3}$ Department of Anesthesiology, Xi'an Beihuan Hospital, Xi'an, Shaanxi 710032, P.R. China

Received October 23, 2019; Accepted December 19, 2019

DOI: $10.3892 /$ etm.2020.8479

\begin{abstract}
Influence of rosiglitazone on the myocardial apoptosis in rats with acute myocardial infarction (AMI) via the Toll-like receptor 4 (TLR4)/nuclear factor- $\kappa \mathrm{B}(\mathrm{NF}-\kappa \mathrm{B})$ signaling pathway was explored. A total of 30 healthy male Sprague-Dawley (SD) rats were randomly divided into group A (Sham group, $\mathrm{n}=10$ ), group B (AMI model group, $\mathrm{n}=10$ ) and group C (AMI model + rosiglitazone group, $n=10$ ) using a random number table. It was observed through $\mathrm{H} \& \mathrm{E}$ staining that group A had myocardial cells with normal morphology and infiltration of few inflammatory factors, while group B had swollen myocardial cells with disorderly and irregular morphology, large and dark-colored nuclei, infiltration of massive inflammatory factors, large amounts of fibrous tissue hyperplasia in the intercellular space, disorderly arranged, thickened and lengthened myocardial fibers with widened gaps. Moreover, group C exhibited infiltration of fewer inflammatory factors and more normal myocardial tissue structure compared with group B. According to the sirius-red staining results, group A had normally arranged myocardial cells with a small amount of collagen hyperplasia, while group B had collagen interstitial hyperplasia and higher content of myocardial collagen than group A. Compared with that in group B, the myocardial collagen deposit was substantially reduced in
\end{abstract}

Correspondence to: Dr Hongzhong Ma, Department of Anesthesiology, The Affiliated Yantai Yuhuangding Hospital of Qingdao University, 20 East Yuhuangding Road, Yantai, Shandong 264000, P.R. China

E-mail: nidaodao19820113@163.com

Dr Xiaoli Feng, Department of Pathology, The Affiliated Yantai Yuhuangding Hospital of Qingdao University, 20 East Yuhuangding Road, Yantai, Shandong 264000, P.R. China

E-mail: 135835721@163.com

*Contributed equally

Key words: TLR4/NF-кB, rosiglitazone, acute myocardial infarction group C. TUNEL staining results showed that the apoptosis rate of rat myocardial cells in group B was obviously higher than that in group $\mathrm{A}(40.37$ vs. 5.23\%), and it was notably lower in group C than that in group B (24.82 vs. 40.37\%). According to the western blot results, the protein expression levels of the inflammatory factors TLR-4 and NF- $\kappa \mathrm{B}$ in rat myocardial tissues were notably raised in group $\mathrm{B}$ compared with those in group $\mathrm{A}$, and they were evidently lower in group $\mathrm{C}$ than those in group B. Rosiglitazone inhibits the TLR4/NF- $\kappa \mathrm{B}$ signaling pathway to produce a myocardioprotective effect.

\section{Introduction}

Acute myocardial infarction (AMI) is a severe disease that is responsible for cardiac structure impairment and cardiac insufficiency (1). Additionally, AMI is not only one of the most hazardous coronary heart diseases, but also an important factor for cardiac function impairment and it will cause death to patients in severe cases (2). People who suffer or died from AMI have become younger in recent years. The main pathophysiological manifestations of AMI include a large area of myocardial necrosis and decline in contractility (3). AMI can cause cardiac insufficiency and various malignant complications, thus seriously affecting the health and living quality of patients (4). Therefore, medical research focuses on how to better prevent and treat AMI (5).

Numerous studies have demonstrated that rosiglitazone can play an anti-inflammatory role in treating such diseases as septic shock and sepsis (6-9) and has been found to produce a myocardioprotective effect in animal experiments. The activated Toll-like receptor 4 (TLR4)/nuclear factor- $\kappa \mathrm{B}(\mathrm{NF}-\kappa \mathrm{B})$ signaling pathway can destroy myocardial tissues, and some studies have proven that myocardial infarction-caused inflammatory responses are directly associated with TLR4, a member of the TLR family. Once binding to the ligand, TLR4 further activates the NF- $\mathrm{B}$ signaling pathway to stimulate increase of the expression of various inflammatory cell genes. Since the correlation between rosiglitazone and the TLR4/NF- $\kappa \mathrm{B}$ signaling pathway remains to be clarified, the rat model of AMI was established in the present study to observe the relationship between rosiglitazone and the 
TLR4/NF- $\mathrm{B}$ signaling pathway and the influence of rosiglitazone on AMI.

\section{Materials and methods}

Laboratory animals. The laboratory animals in the present study were provided by the Experimental Animal Center of Shandong University. A total of 30 male Sprague-Dawley (SD) rats weighing 180-200 $\mathrm{g}$ were fed in the specific pathogen-free animal room at $25^{\circ} \mathrm{C}$, humidity of $45 \%$ and a light-dark cycle of $12 / 12 \mathrm{~h}$ and they had free access to food and water. This study was approved by the Animal Ethics Committee of The Affiliated Yantai Yuhuangding Hospital of Qingdao University Animal Center (Yantai, China).

Experimental instruments and reagents. Color Doppler ultrasound diagnostic apparatus, heart M3 S probe, electrocardiogram monitor and inverted phase-contrast microscope were from Philips, and ultra-clean animal bench, 5-0 Prolene suture, ketamine hydrochloride injection, atropine injection and $10 \%$ formaldehyde from Olympus.

Animal grouping and AMI modeling. A total of 30 healthy male SD rats were selected and randomly assigned into group A (Sham group, $n=10$ ), group B (AMI model group, $\mathrm{n}=10$ ) and group $\mathrm{C}(\mathrm{AMI}$ model + rosiglitazone group, $\mathrm{n}=10$ ) using a random number table.

The rats in group $\mathrm{C}$ were intraperitoneally injected with rosiglitazone at $3 \mathrm{mg} / \mathrm{kg}$ once daily for 1 week, while those in both group A and group B were intraperitoneally injected with the same volume of normal saline once daily.

In the present study, $3 \mathrm{mg} / \mathrm{kg}$ rosiglitazone was intraperitoneally injected at $1 \mathrm{~h}$ before medicating and modeling, and the AMI model was established by permanent ligation of the left anterior descending artery in the rats. After being anesthetized using $1 \mathrm{~g} / \mathrm{kg}$ urethane (Qing xi), the rats were ventilated using a TKR-200C ventilator (Jiangxi Teli Anaesthesia \& Respiration Equipment Co.) at a stroke volume of $12 \mathrm{ml} / \mathrm{kg}$ and a frequency of $60 \mathrm{times} / \mathrm{min}$. Then the chest was opened through the left chest incision between the 2 nd and 4 th ribs. Suture was performed at $1 / 3$ of the distal left anterior descending using 6-0 silk thread with a silk knot, and the tubule was placed between the ligation thread and myocardial tissues. Except the ligation of the left anterior descending artery, the rats in group A underwent the same surgical procedures.

Hematoxylin-eosin $(H \& E)$ staining. After the last administration of drugs, all the rats to be detected were sacrificed through dislocation, and the heart was removed and treated with $4 \%$ paraformaldehyde/PBS ( $\mathrm{pH} 7.4$ ) at $4^{\circ} \mathrm{C}$ for $48 \mathrm{~h}$. The tissues were washed using flowing water and dehydrated in $70,80,95$ and $100 \%$ gradient ethanol, removed using xylene, and then they were embedded in paraffin ( $2 \mu \mathrm{m}$ thick). Finally, the paraffin-embedded tissues were stained using the H\&E staining kit (Beyotime Biotechnology) strictly according to the manufacturer's specifications.

Determination of messenger ribonucleic acid (mRNA) expression of high-mobility group box 1 (HMGB1), tumor necrosis factor- $\alpha(T N F-\alpha)$ and interleukin (IL)- 6 via
Table I. Primer sequences.

\begin{tabular}{|c|c|}
\hline Name & Primer sequences (C 5'-3') \\
\hline HMGB1 & $\begin{array}{l}\text { F: AAGAAGTGCTCAGAGAGGTGGAAG } \\
\text { R: TAGTTTCTTCGCAACATCACCA }\end{array}$ \\
\hline TNF- $\alpha$ & $\begin{array}{l}\text { F: } \text { TGAACTTCGGGGTGATCGGT } \\
\text { R: GCTACGGGCTTGTCACTCG }\end{array}$ \\
\hline IL-6 & $\begin{array}{l}\text { F: ATTGTATGAACAGCGATGATGC } \\
\text { R: AGAAACGGAACTCCAGAAGACC }\end{array}$ \\
\hline GAPDH & $\begin{array}{l}\text { F: CTTCCGTGTTCCTACCCC } \\
\text { R: CCCAGGATGCCCTTTAGTG }\end{array}$ \\
\hline
\end{tabular}

HMGB1, high-mobility group box 1 ; TNF- $\alpha$, tumor necrosis factor- $\alpha$; IL-6, intreleukin-6; F, forward; R, reverse.

reverse transcription-quantitative polymerase chain reaction $(R T-q P C R)$. RT and qPCR were performed to detect the mRNA expression of HMGB1, TNF- $\alpha$ and IL-6 in rat myocardial tissues in the three groups. The tissue samples were taken out of a cryopreservation tube, drained and ground using liquid nitrogen in a $5 \mathrm{ml}$ tube. After the samples were completely homogenized using a tissue homogenizer, the liquid was transferred to clean Eppendorf (EP) tubes $(1.5 \mathrm{ml})$ and let stand at room temperature for 5-10 min to fully lyse the tissues. Subsequently, the lysed tissues were centrifuged at $4^{\circ} \mathrm{C}$, $1,050 \mathrm{x} g$ for $5 \mathrm{~min}$, and with the deposits discarded, the tissues were added with chloroform at $200 \mu \mathrm{l}$ of chloroform/1 ml of TRIzol (Invitrogen; Thermo Fisher Scientific, Inc.), shaken and mixed evenly and placed at room temperature for $15 \mathrm{~min}$. The mixture was centrifuged at $4^{\circ} \mathrm{C}, 1,050 \mathrm{xg}$ for $15 \mathrm{~min}$, and the supernatant fluid-phase was aspirated into another centrifugal tube, added with isopropanol that was 0.7-1-fold volume of the supernatant, placed at room temperature for 10-30 min and centrifuged at $4^{\circ} \mathrm{C}, 10,500 \mathrm{x}$ for $10 \mathrm{~min}$. With the supernatant discarded, RNAs were deposited at the bottom of tubes, and the centrifugal tubes were added with $75 \%$ ethanol at $1 \mathrm{ml}$ of ethanol/1 $\mathrm{ml}$ of TRIzol, moderately shaken to suspend the precipitates, and centrifuged at $4^{\circ} \mathrm{C}, 10,500 \mathrm{x} \mathrm{g}$ for $5 \mathrm{~min}$. After the supernatant was removed, the products were blown dry on an ultra-clean bench for 10-20 min, added with 10-50 $\mu \mathrm{l}$ of diethyl pyrocarbonate (DEPC)-treated $\mathrm{dd}_{2} \mathrm{O}$ (Beyotime) to dissolve the precipitates. Finally, the concentration of RNAs was determined using OneDrop micro-spectrophotometer. RT reaction was performed in a system comprising $4.5 \mu \mathrm{l}$ of RNase-free $\mathrm{ddH}_{2} \mathrm{O}, 2 \mu \mathrm{l}$ of $5 \mathrm{X}$ RT reaction buffer, $0.5 \mu \mathrm{l}$ of random primers, $0.5 \mu \mathrm{l}$ of oligo(dT), $0.5 \mu \mathrm{l}$ of reverse transcriptase and $2 \mu \mathrm{l}$ of RNAs. The samples of complementary DNAs (cDNAs) were divided into three groups and diluted 20-fold in each group, $3 \mu \mathrm{l}$ of which was used for PCR amplification. The amplification level of the target gene was measured via 5\% agarose gel electrophoresis. Then the LabWorks 4.0 image acquisition and analysis software was employed for quantification and data processing. The above operations were repeated three times in each group to obtain reliable data. In the present study, the change in the relative expression levels of the target genes were analyzed using $2^{-\Delta \Delta \mathrm{Ct}}$. The primer sequences used in this study are shown in Table I. 
Group A

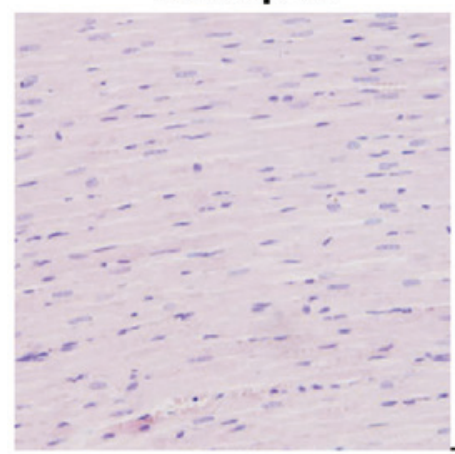

Group B

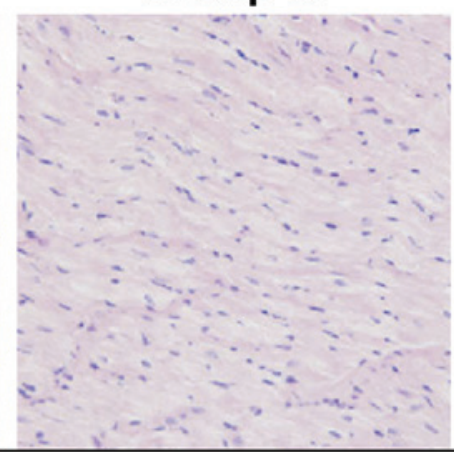

Group C

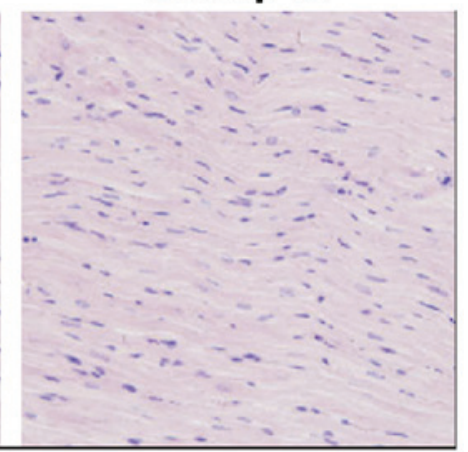

Figure 1. Rosiglitazone notably improves the morphology of rat myocardial tissues.

Detection of protein expression of TLR-4 and NF- $\kappa B$ via western blotting. The tissue lysis buffer was first prepared as follows: an appropriate volume of radioimmunoprecipitation assay (RIPA) was taken and mixed evenly with phenylmethylsulfonyl fluoride (PMSF) at a ratio of 100:1 (Beyotime). Then the rat myocardial tissues in the three groups were isolated, sheared into small blocks, added with the lysis buffer at 10:1, homogenized by the tissue homogenizer and transferred into EP tubes. After centrifugation using a low-temperature high-speed centrifugal machine at $4^{\circ} \mathrm{C}, 13,500 \mathrm{x}$ g for $30 \mathrm{~min}$, the protein supernatant was aspirated, followed by $10 \mathrm{~min}$ of heat bath at $95^{\circ} \mathrm{C}$ for protein denaturalization. The prepared protein samples were stored at $-80^{\circ} \mathrm{C}$ in a refrigerator for later use, and they were quantified using bicinchoninic acid (BCA) kit (Pierce; Thermo Fisher Scientific, Inc.). After quantification, the sodium dodecyl sulphate-polyacrylamide gel electrophoresis (SDS-PAGE) gel was prepared, and the protein samples were loaded into the SDS-PAGE gel wells for electrophoresis under the constant voltage of $80 \mathrm{~V}$ for $2.5 \mathrm{~h}$. Subsequently, the proteins were transferred onto polyvinylidene fluoride (PVDF) membranes (Millipore) by the semi-dry transfer method, and the PVDF membranes were immersed in the Tris-buffered saline with Tween-20 (TBST) buffer containing 5\% skim milk powder, shaken slowly using a shaker for $1 \mathrm{~h}$ and sealed, followed by dilution of antibodies using 5\% skim milk powder. At the completion of the incubation with the primary antibodies, the membranes were rinsed using TBST 3 times (10 min/time), incubated with the secondary antibodies at room temperature for $2 \mathrm{~h}$ and rinsed using TBST and TBS twice and once, respectively (10 $\mathrm{min} / \mathrm{time})$. The resulting proteins were detected using electrochemiluminescence (ECL) reagent and exposed in a dark room. Finally, the relative expression level of proteins was analyzed using Image-Pro Plus v6 software (Media Cybernetics).

Determination of myocardial collagen content. Paraffinembedded sections (4-6 $\mu$ m thick) were prepared, added with lapis lazuli liquid and then rinsed using running water for $1 \mathrm{~min}$. Subsequently, the sections were dehydrated with absolute alcohol and stained with sirius red-saturated picric acid buffer for 15-30 min, followed by image analysis and observation of stained morphology under a common light microscope. Finally, the coverage area of collagen was measured using ImageJ software.
Evaluation of cell apoptosis via terminal deoxynucleotidyl transferase-mediated dUTP nick end labeling (TUNEL) assay. The prepared paraffin-embedded sections were subjected to TUNEL staining to detect apoptosis of rat myocardial cells in each group strictly in accordance with the experimental operations in the manufacturer's specifications of the kit. The coloring was observed, and 150 cells were counted in each randomly selected 6 fields (x400), in which the apoptotic cells were brown. Finally, the apoptosis rate of myocardial cells was calculated: the number of apoptotic cells/the total number of cells $\times 100 \%$.

Statistical analysis. All the tests were performed in 3 parallel groups or in triplicate, and the results were expressed as mean \pm standard deviation. Intra-group statistical differences were analyzed using t-test, and $\mathrm{P}<0.05$ and $\mathrm{P}<0.01$ denote statistically significant difference, respectively.

\section{Results}

Rosiglitazone substantially improves the morphology of rat myocardial tissues. Based on the H\&E staining results, group A had myocardial tissues with normal morphology and infiltration of few inflammatory factors, group B had swollen and distorted myocardial tissues with disorderly and irregular morphology, large and dark-colored nuclei, infiltration of massive inflammatory factors, large amounts of fibrous tissue hyperplasia in the intercellular space, disorderly arranged, thickened and lengthened myocardial fibers with widened gaps, and group $\mathrm{C}$ had slightly disorderly arranged myocardial tissues with milder swelling and a small amount of fibrous tissue hyperplasia. However, group $\mathrm{C}$ exhibited infiltration of fewer inflammatory factors and more normal myocardial tissue structure than group B. The above results indicate that intraperitoneal injection of rosiglitazone can substantially improve the morphology of myocardial tissues in rats (Fig. 1).

Comparison of collagen in myocardial tissues among all groups of rats. Group A had normally arranged myocardial cells with a small amount of collagen hyperplasia, while group B had collagen interstitial hyperplasia and notably higher content of myocardial collagen than group $\mathrm{A}(\mathrm{P}<0.05)$. There was a smaller amount of myocardial collagen deposited in group $\mathrm{C}$ than in group B (Fig. 2). 
A

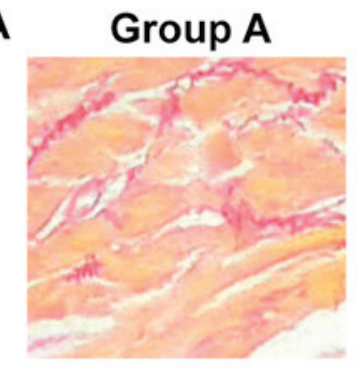

Group B

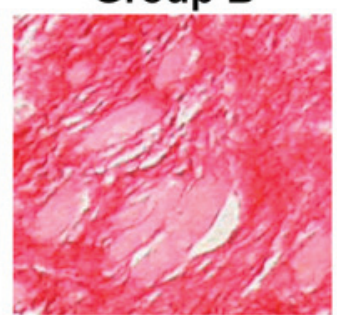

Group C

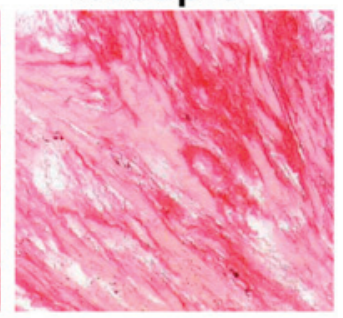

B

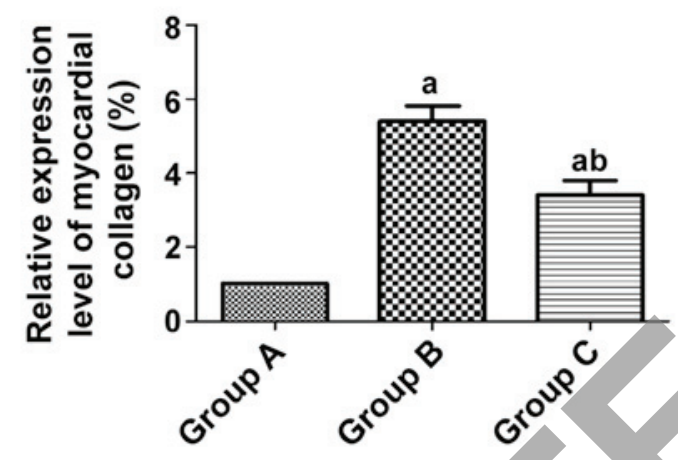

Figure 2. Content of collagen in rat myocardial tissues in all groups. (A) Staining images of rat myocardial collagen in each group. (B) Relative expression level of myocardial collagen of each group of rats. ${ }^{a} \mathrm{P}<0.05$ vs. group $\mathrm{A} ;{ }^{\mathrm{b}} \mathrm{P}<0.05$ vs. group $\mathrm{B}$.

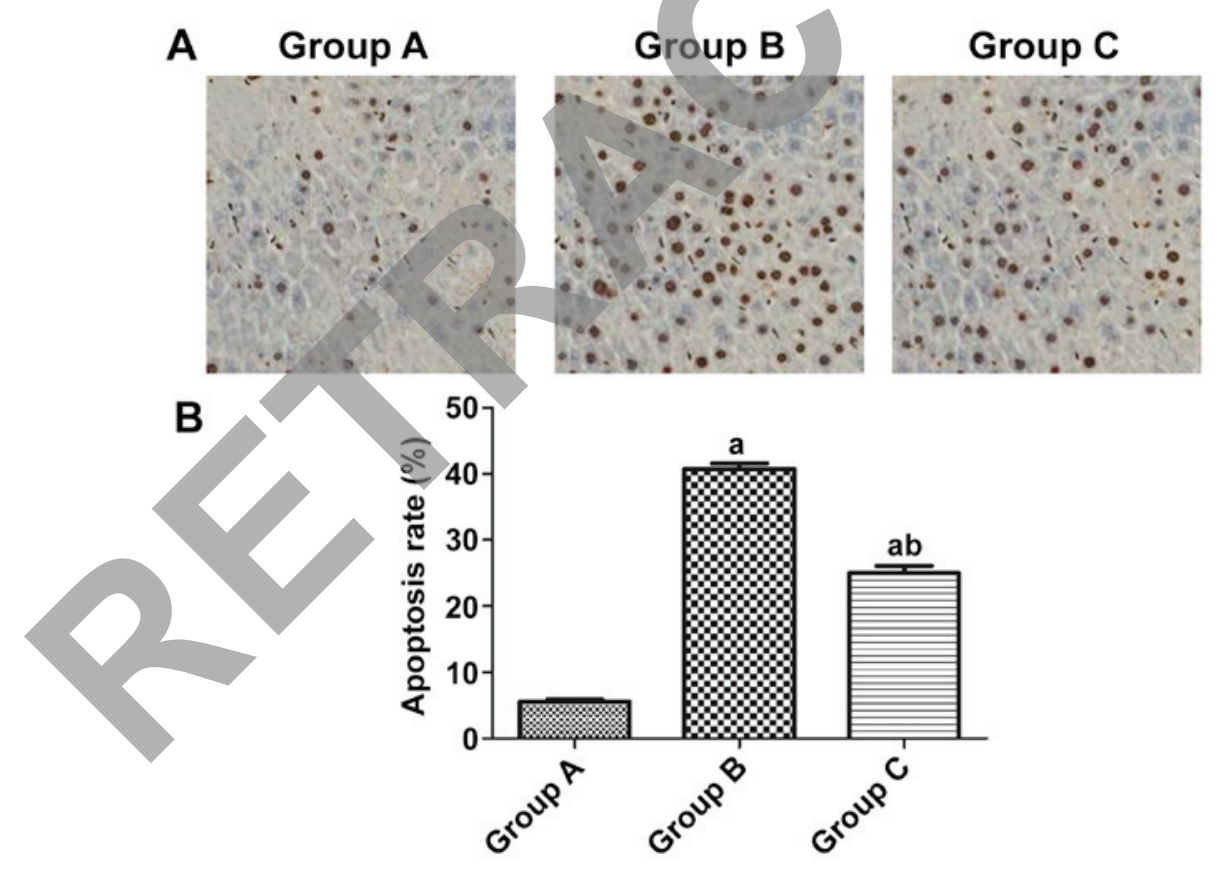

Figure 3. Apoptosis of rat myocardial cells in each group. (A) Comparison of apoptosis level of rat myocardial cells among all groups. (B) Apoptosis rate of rat myocardial cells in each group. ${ }^{a} \mathrm{P}<0.05$ vs. group $\mathrm{A} ;{ }^{\mathrm{b}} \mathrm{P}<0.05$ vs. group $\mathrm{B}$.

Apoptosis in rat myocardial tissues detected via TUNEL assay. According to the results, the apoptosis rate of rat myocardial cells was obviously higher in group B than that in group A $(40.37$ vs. $5.23 \%)(\mathrm{P}<0.05)$, and it was notably lower in group C than that in group B (24.82 vs. $40.37 \%)$ $(\mathrm{P}<0.05)$ (Fig. 3).

mRNA expression of HMGB1, TNF- $\alpha$ and IL- 6 in myocardial tissues detected via real-time PCR. It was found through real-time PCR that the mRNA expression levels of the inflammatory factors HMGB1, TNF- $\alpha$ and IL-6 in rat myocardial tissues were notably elevated in group B compared with those in group $\mathrm{A}(\mathrm{P}<0.05)$, and they were evidently lower in group $\mathrm{C}$ than those in group $\mathrm{B}(\mathrm{P}<0.05)$ (Fig. 4).

Protein expression of TLR-4 and NF- $\kappa B$ in rat myocardial tissues in each group detected via western blotting. According to the western blot results, the protein expression levels of the inflammatory factors TLR-4 and NF- $\mathrm{NB}$ in rat myocardial tissues were notably higher in group B than those in group A $(\mathrm{P}<0.05)$, and they were evidently lower in group $\mathrm{C}$ than those in group $\mathrm{B}(\mathrm{P}<0.05)$ (Fig. 5). 


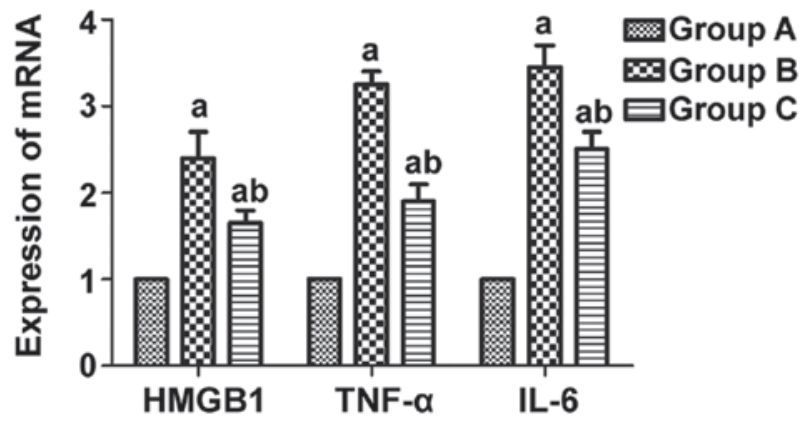

Figure 4. mRNA expression of HMGB1, TNF- $\alpha$ and IL-6 in rat myocardial tissues in each group. ${ }^{\text {a }}<<0.05$ vs. group $\mathrm{A} ;{ }^{\mathrm{b}} \mathrm{P}<0.05$ vs. group $\mathrm{B}$. HMGB1, high-mobility group box 1 ; TNF- $\alpha$, tumor necrosis factor- $\alpha$; IL-6, interleukin- 6 .

\section{Discussion}

AMI, a severe coronary heart disease $(10,11)$, is mainly caused by dramatic reduction in blood supply for coronary arteries due to coronary atherosclerosis $(12,13)$, which is often accompanied by arrhythmia, shock, heart failure or other complications.

It was observed through the H\&E staining that group A had myocardial cells with normal morphology and infiltration of few inflammatory factors, while group B had swollen myocardial cells with disorderly and irregular morphology, large and dark-colored nuclei, infiltration of massive inflammatory factors, large amounts of fibrous tissue hyperplasia in the intercellular space, disorderly arranged, thickened and lengthened myocardial fibers with widened gaps. Moreover, compared with group B, group C exhibited infiltration of fewer inflammatory factors and more normal myocardial tissue structure. The above results imply that intraperitoneal injection of rosiglitazone can greatly improve the morphology of myocardial tissues in rats. It was found by Monami et al (14) through a study that after myocardial infarction, inflammatory responses occur in human bodies, and rosiglitazone is capable of protecting myocardial cells, inhibiting inflammatory factors and resisting myocardial dilatation and healing. The present study explored the relationship between rosiglitazone and myocardial tissues, and it was discovered that the intervention with rosiglitazone reduced infiltration of inflammatory factors, alleviated swelling of myocardial cells and effectively repressed fibrous tissue hyperplasia, thereby treating AMI.

According to the results of this study, group B had considerably higher mRNA expression levels of the inflammatory factors HMGB1, TNF- $\alpha$ and IL-6 in rat myocardial tissues than group $\mathrm{A}(\mathrm{P}<0.05)$, and they were evidently lower in group $\mathrm{C}$ than those in group $\mathrm{B}(\mathrm{P}<0.05)$. The study of Rietbergen et al (15) manifested that as an inflammatory factor, HMGB1 can also promote the upregulation of pro-inflammatory factors, such as TNF- $\alpha$ and IL-6. Consistent with the above conclusion, the findings in this study showed that the mRNA expression of HMGB1 was obviously raised in myocardial tissues after AMI, which was accompanied by the increase in the levels of TNF- $\alpha$ and IL-6. Moreover, the intervention with rosiglitazone decreased the mRNA expression of HMGB1 in myocardial tissues, thus relieving AMI. The above
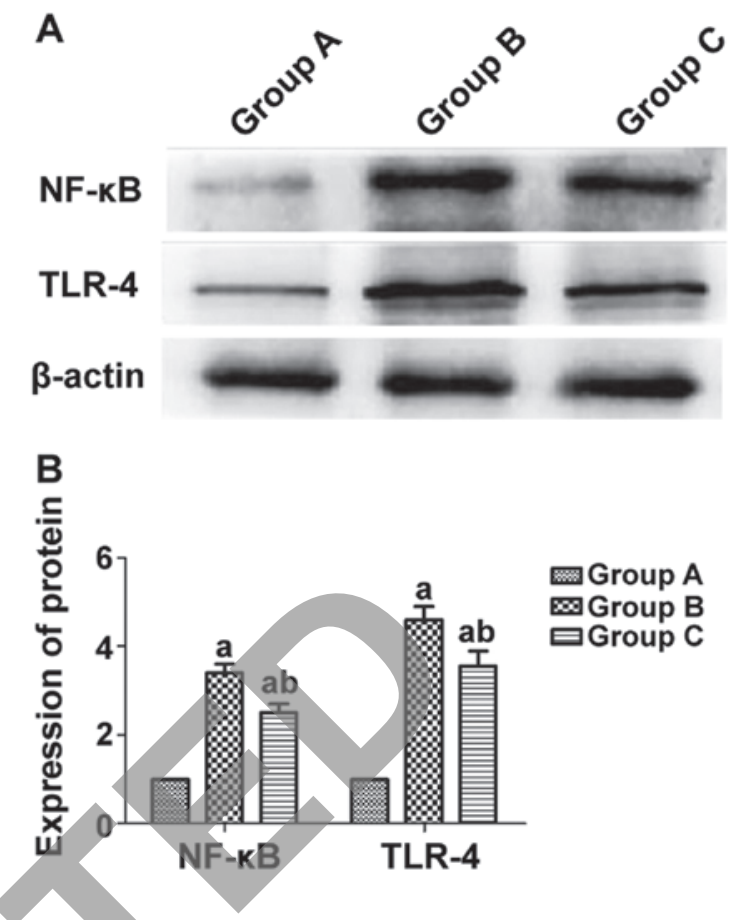

Figure 5. Protein expression of TLR-4 and NF- $\kappa \mathrm{B}$ in rat myocardial tissues in each group. (A) Protein images of TLR-4 and NF- $\kappa B$ in each group of rats. (B) Relative protein expression levels of TLR-4 and NF- $\kappa \mathrm{B}$ in each group of rats. ${ }^{\mathrm{P}}<0.05$ vs. group $\mathrm{A} ;{ }^{b} \mathrm{P}<0.05$ vs. group $\mathrm{B}$. TLR-4, Toll-like receptor 4 ; $\mathrm{NF}-\kappa \mathrm{B}$, nuclear factor- $\kappa \mathrm{B}$.

results suggest that rosiglitazone can suppress the expression of HMGB1, TNF- $\alpha$ and IL- 6 to treat myocardial infarction.

Group B had higher protein expression levels of TLR4 and $\mathrm{NF}-\kappa \mathrm{B}$ in rat myocardial tissues than group $\mathrm{A}(\mathrm{P}<0.05)$, and they were obviously lower in group $\mathrm{C}$ than those in group $\mathrm{B}$ $(\mathrm{P}<0.05)$. According to the study of Psaty and Furberg (16), rosiglitazone can exert an anti-inflammatory effect (17) via decreasing the levels of CRP, TNF- $\alpha$, IL- 6 and MCP-1 and inhibiting the NF- $\mathrm{KB}$ signaling pathway. To confirm that rosiglitazone represses the TLR4 and NF- $\kappa \mathrm{B}$ to treat AMI, rosiglitazone was administered in vitro for intervention in this study, and it was found that rosiglitazone was negatively correlated with the activity of TLR4 and NF- $\mathrm{kB}$ signals, namely rosiglitazone can weaken the activity of TLR 4 and NF- $\mathrm{KB}$ signals to improve the disease, which agrees with the results of the study of Psaty and Furberg (16).

In addition, group A exhibited normally arranged myocardial cells with a small amount of collagen hyperplasia, and group B had disorderly arranged myocardial cells, collagen interstitial hyperplasia and much more content of myocardial collagen than both group A and group $\mathrm{C}(\mathrm{P}<0.05)$. Additionally, group $\mathrm{C}$ showed a smaller amount of myocardial collagen hyperplasia than group B and regularly arranged cells. According to the findings of the study conducted by Tao et al (18), rosiglitazone reduces the expression of TLRQ in epithelial cells to reduce or inhibit the activation of NF- $\mathrm{kB}$, thereby suppressing the expression of myocardial collagen, and after activation by rosiglitazone, myocardial interstitium and collagen hyperplasia decline. VSL3 can inhibit the expression of myocardial collagen, but it is not so efficacious as 5-ASA and rosiglitazone (19). Rosiglitazone explored in this 
study suppresses the expression of TLRQ in myocardial cells, and since excessive amounts of myocardial interstitium can affect cardiac function and myocardial collagen hyperplasia also does harm to the heart, rosiglitazone exerts a therapeutic effect on myocardial infarction through reducing myocardial interstitium and collagen, which agree with the results of the study of Tao et al (18).

Lastly, the apoptosis rate of rat myocardial cells was obviously higher in group B than that in group A (40.37 vs. 5.23\%) $(\mathrm{P}<0.05)$, and it was notably lower in group $\mathrm{C}$ than that in group B (24.82 vs. $40.37 \%)(\mathrm{P}<0.05)$. Matchin et al $(20)$ found that caspase is a protease in cell apoptosis. Rosiglitazone is able to activate caspase-3 gene to initiate cell apoptosis (20). The present study found that apoptosis level of myocardial cells was very low in normal rats, while there were large numbers of apoptotic cells in myocardial infarction rats. Additionally, rosiglitazone lowered the content of apoptosis factors by inhibiting the pro-apoptotic factors to repress cell apoptosis and treat the disease. The above results are consistent with those of the study conducted by Matchin et al (20).

In conclusion, it is concluded that rosiglitazone can treat AMI to a certain extent through inhibiting the TLR4/NF- $\kappa B$ signaling pathway.

\section{Acknowledgements}

Not applicable.

\section{Funding}

No funding was received.

\section{Availability of data and materials}

All data generated or analyzed during this study are included in this published article.

\section{Authors' contributions}

HM, JD and XF designed the study and performed the experiments, HM, YZ and HW established the animal models, JD and SD collected the data, AH and JM analyzed the data, HM JD and XF prepared the manuscript. All authors read and approved the final manuscript.

\section{Ethics approval and consent to participate}

This study was approved by the Animal Ethics Committee of The Affiliated Yantai Yuhuangding Hospital of Qingdao University Animal Center (Yantai, China).

\section{Patients consent for publication}

Not applicable.

\section{Competing interests}

The authors declare that they have no competing interests.

\section{References}

1. Milazzo V, De Metrio M, Cosentino N, Marenzi G and Tremoli E: Vitamin D and acute myocardial infarction. World J Cardiol 9: 14-20, 2017.

2. Komici K, Vitale DF, Leosco D, Mancini A, Corbi G, Bencivenga L, Mezzani A, Trimarco B, Morisco C, Ferrara N, et al: Pressure injuries in elderly with acute myocardial infarction. Clin Interv Aging 12: 1495-1501, 2017.

3. Burls A, Cabello JB, Emparanza JI, Bayliss S and Quinn T: Oxygen therapy for acute myocardial infarction: A systematic review and meta-analysis. Emerg Med J 28: 917-923, 2011.

4. Hirachan A and Maskey A: Acute myocardial infarction following electroconvulsive therapy in a Schizophrenic patient. Egypt Heart J 69: 71-73, 2017

5. Yandrapalli S, Jolly G, Horblitt A, Sanaani A and Aronow WS: Cardiovascular benefits and safety of non-insulin medications used in the treatment of type 2 diabetes mellitus. Postgrad Med 129: 811-821, 2017.

6. von Lewinski D, Kolesnik E, Wallner M, Resl M and Sourij H: New antihyperglycemic drugs and heart failure: Synopsis of basic and clinical data. BioMed Res Int 2017: 1253425, 2017.

7. Gilbert RE: Finerenone in diabetic kidney disease - So far, so good. J Diabetes Complications 31: 651-652, 2017.

8. Cutshall BT, Twilla JD, Olinger AS and Oliphant CS: A review on cardiovascular effects of newer hypoglycaemic medications. Ann Med 49: 603-612, 2017.

9. Cheng JW, Badreldin HA, Patel DK and Bhatt SH: Antidiabetic agents and cardiovascular outcomes in patients with heart diseases. Curr Med Res Opin 33: 985-992, 2017.

10. Zhou M, Zou YG, Xue YZ, Wang XH, Gao H, Dong HW and Zhang Q: Long non-coding RNA H19 protects acute myocardial infarction through activating autophagy in mice. Eur Rev Med Pharmacol Sci 22: 5647-5651, 2018.

1. Chapman AR, Anand A, Boeddinghaus J, Ferry AV, Sandeman D, Adamson PD, Andrews J, Tan S, Cheng SF, D'Souza M, et al: Comparison of the efficacy and safety of early rule-out pathways for acute myocardial infarction. Circulation 135: 1586-1596, 2017.

12. Curry LA, Brault MA, Linnander EL, McNatt Z, Brewster AL, Cherlin E, Flieger SP, Ting HH and Bradley EH: Influencing organisational culture to improve hospital performance in care of patients with acute myocardial infarction: A mixed-methods intervention study. BMJ Qual Saf 27: 207-217, 2018.

13. Yu B, Zhang G, An Y and Wang W: Morroniside on anti-inflammation activities in rats following acute myocardial infarction. Korean J Physiol Pharmacol 22: 17-21, 2018.

14. Monami M, Bigiarini M, Rotella CM and Mannucci E: Inaccuracy in meta-analysis on rosiglitazone and myocardial infarction. Nutr Metab Cardiovasc Dis 21: e7-e8, 2011.

15. Rietbergen C, Stefansdottir G, Leufkens HG, Knol MJ, De Bruin ML and Klugkist I: Evidence synthesis in harm assessment of medicines using the example of rosiglitazone and myocardial infarction. Front Med (Lausanne) 4: 228, 2018.

16. Psaty BM and Furberg CD: The record on rosiglitazone and the risk of myocardial infarction. N Engl J Med 357: 67-69, 2007.

17. Zhang G, Zhang X, Li D, Tian J and Jiang W: Long-term oral atazanavir attenuates myocardial infarction-induced cardiac fibrosis. Eur J Pharmacol 828: 97-102, 2018.

18. Tao L, Wang Y, Gao E, Zhang H, Yuan Y, Lau WB, Chan L, Koch WJ and Ma XL: Adiponectin: An indispensable molecule in rosiglitazone cardioprotection following myocardial infarction. Circ Res 106: 409-417, 2010.

19. Hally KE, La Flamme AC, Larsen PD and Harding SA: Platelet Toll-like receptor (TLR) expression and TLR-mediated platelet activation in acute myocardial infarction. Thromb Res 158: 8-15, 2017.

20. Matchin YG, Atanesyan RV, Kononets EN, Danilov NM, Bubnov DS and Ageev FT: The first experience of using very long stents covered with sirolimus $(4060 \mathrm{~mm})$ in the treatment of patients with extensive and diffuse lesions of the coronary arteries. Kardiologiia 57: 19-26, 2017 (In Russian).

This work is licensed under a Creative Commons Attribution-NonCommercial-NoDerivatives 4.0 International (CC BY-NC-ND 4.0) License. 